\section{(C) OPEN ACCESS}

\title{
Bulky DNA adducts, microRNA profiles, and lipid biomarkers in Norwegian tunnel finishing workers occupationally exposed to diesel exhaust
}

\author{
Iselin Rynning, ${ }_{1}^{1}$ Volker M Arlt, ${ }^{2,3}$ Kristyna Vrbova, ${ }^{4}$ Jiří Neča, ${ }^{5}$ Pavel Rossner $\mathrm{Jr}_{1}{ }^{4}$ \\ Jiri Klema, ${ }^{6}$ Bente Ulvestad, ${ }^{7}$ Elisabeth Petersen, ${ }^{8}$ Øivind Skare, ${ }^{7}$ Aage Haugen, \\ David H Phillips, ${ }^{2,3}$ Miroslav Machala, ${ }^{5}$ Jan Topinka, ${ }^{4}$ Steen Mollerup ${ }^{1}$
}

\begin{abstract}
- Additional material is published online only. To view please visit the journal online (http://dx.doi.org/10.1136/ oemed-2018-105445).
\end{abstract}

For numbered affiliations see end of article.

\section{Correspondence to} Dr Steen Mollerup, Section for Toxicology and Biological Work Environment, Department of Chemical and Biological Work Environment, National Institute of Occupational Health, Oslo 0304, Norway:

steen.mollerup@stami.no

Received 21 August 2018 Revised 4 October 2018 Accepted 21 October 2018 Published Online First 13 November 2018

\section{Check for updates}

(c) Author(s) (or their employer(s)) 2019. Re-use permitted under CC BY-NC. No commercial re-use. See rights and permissions. Published by BMJ.

To cite: Rynning I,

Arlt VM, Vrbova K, et al.

Occup Environ Med

2019:76:10-16.

\section{ABSTRACT}

Objectives This study aimed to assess the biological impact of occupational exposure to diesel exhaust (DE) including DE particles (DEP) from heavy-duty dieselpowered equipment in Norwegian tunnel finishing workers (TFW).

Methods TFW $(n=69)$ and referents $(n=69)$ were investigated for bulky DNA adducts (by ${ }^{32} \mathrm{P}$-postlabelling) and expression of microRNAs (miRNAs) (by small RNA sequencing) in peripheral blood mononuclear cells (PBMC), as well as circulating free arachidonic acid (AA) and eicosanoid profiles in plasma (by liquid chromatography-tandem mass spectrometry).

Results PBMC from TFW showed significantly higher levels of DNA adducts compared with referents. Levels of DNA adducts were also related to smoking habits. Seventeen miRNAs were significantly deregulated in TFW. Several of these miRNAs are related to carcinogenesis, apoptosis and antioxidant effects. Analysis of putative miRNA-gene targets revealed deregulation of pathways associated with cancer, alterations in lipid molecules, steroid biosynthesis and cell cycle. Plasma profiles showed higher levels of free AA and 15-hydroxyeicosatetraenoic acid, and lower levels of prostaglandin $D_{2}$ and 9-hydroxyoctadecadienoic acid in TFW compared with referents.

Conclusion Occupational exposure to DE/DEP is associated with biological alterations in TFW potentially affecting lung homoeostasis, carcinogenesis, inflammation status and the cardiovascular system. Of particular importance is the finding that tunnel finishing work is associated with an increased level of DNA adducts formation in PBMC.

\section{INTRODUCTION}

Occupational exposure to diesel exhaust (DE) is a great health concern, ${ }^{12}$ and is associated with respiratory and cardiovascular diseases (CVD). ${ }^{3}$ $\mathrm{DE}$ is classified as carcinogenic to humans, ${ }^{2}$ and this is supported by in vitro studies. ${ }^{45}$ Of particular concern is the use of heavy-duty diesel engines in enclosed environments such as underground mining and tunnel construction. ${ }^{1}$ Tunnel finishing workers (TFW) are fitters performing work related to, that is, electrical installation, rock support, and water and frost protection in road and railway tunnels. Despite reduction efforts, TFW are highly exposed

\section{Key messages}

What is already known about this subject?

- Exposure to diesel exhaust (DE) including DE particles (DEP) is carcinogenic to humans, and is associated with respiratory and cardiovascular diseases.

- Despite changes in diesel technology and stringent emission restrictions, high air concentrations of DE/DEP from heavy-duty diesel-powered equipment during tunnel finishing work in Norway are reported.

- Biological effects related to occupational exposure to DE in tunnel finishing workers are not known.

What are the new findings?

- Occupational exposure to DE following tunnel finishing work in Norway is associated with increased levels of bulky DNA adducts and deregulation of microRNAs in peripheral blood mononuclear cells, as well as altered plasma arachidonic acid and eicosanoid profiles.

How might this impact on policy or clinical practice in the foreseeable future?

- More attention should be directed towards clarifying biological effects of occupational exposure to $D E$, in particular in relation to tunnel finishing work.

- This study may have implications for risk assessment and preventive strategies concerning occupational exposure to DE.

to DE from heavy-duty diesel-powered equipment. ${ }^{6}$ Using elemental carbon (EC) as a marker of DE, the geometric mean (GM) EC concentration measured from personal full-shift air samplers obtained from three tunnels during finishing work was $37.8 \mu \mathrm{g} / \mathrm{m}^{3}$ $\left(\mathrm{SD}=2.7 \mu \mathrm{g} / \mathrm{m}^{3}\right)$. GM level of $\mathrm{NO}$, was $128.0 \mu \mathrm{g} / \mathrm{m}^{3}$ $\left(\mathrm{SD}=2.9 \mu \mathrm{g} / \mathrm{m}^{3}\right){ }^{6}$ The biological impact of working in such an environment is not clear.

Several of the observed adverse effects of DE are associated with the particulate phase. ${ }^{3}$ DE particles (DEP) are composed of EC cores with various amounts of adsorbed compounds, including polycyclic aromatic hydrocarbons (PAHs), nitro-PAHs and some metals. ${ }^{3}$ The chemical characteristics of DEP 
are affected by the fuel source, engine-type, exhaust after-treatment techniques, and operating conditions. ${ }^{1}$ Exposure to DEP increases airway and systemic inflammation, which may induce oxidative stress and DNA damage. ${ }^{357}$ Gaseous $\mathrm{NO}_{2}$ in DE may also cause proinflammatory reactions and oxidative stress, ${ }^{8}$ and an independent role for both acute and chronic $\mathrm{NO}_{2}$ exposure as risk factors for CVD development has been indicated. ${ }^{9}$

PAHs induce cytochrome P450 monooxygenases, which are key metabolising enzymes in PAH-bioactivation to diol-epoxides, radical cations and o-quinones. ${ }^{10}$ These reactive metabolites can directly affect DNA by forming adducts and initiating carcinogenesis. Peripheral blood mononuclear cells (PBMC) are easily accessible and have been identified as potential surrogates for PAH-exposed lung tissue. ${ }^{11}$ An association between DNA adduct levels in white blood cells (WBC) and risk of lung cancer in highly PAH-exposed individuals has been reported. ${ }^{12}$ Significantly increased levels of DNA adducts were found in lymphocytes from DE-exposed bus maintenance and truck terminal workers, ${ }^{13} 14$ and a recent study reported significantly increased levels of DNA-strand breaks in leucocytes following DE exposure. ${ }^{15}$

Epigenetic changes are strongly associated with environmental exposures and are mechanistically linked to adverse health effects. ${ }^{16}$ miRNA are single-stranded, short non-coding RNA sequences $(\sim 22$ nucleotides) that post-transcriptionally can regulate gene expression. Deregulations of several miRNAs were identified from studies on exposure to DEP and air pollution. ${ }^{16}$ Altered expression of four miRNAs in PBMC after controlled short-term exposure of human participants to DE has been reported. ${ }^{17}$ In a study of foundry workers exposed to metalrich particulate matter (PM), several miRNAs affecting candidate inflammatory genes were found to be deregulated. ${ }^{18}$ Little is known, however, about effects of occupational exposure to $\mathrm{DE} / \mathrm{DEP}$ on miRNA expression, in particular regarding tunnel finishing work.

Enzymatic and non-enzymatic oxidation of arachidonic acid (AA) and its precursor linoleic acid yields prostaglandins (PGs), hydroxyeicosatetraenoic acids (HETEs) and hydroxyoctadecadienoic acid (HODE) lipid mediators with implications for inflammation, CVD and carcinogenesis. ${ }^{7} 1920$ Plasma lipid peroxidation products are suitable biomarkers of the biologically effective dose of PM and are shown to reflect oxidative stress in the airways. ${ }^{21}$ Increased levels of 8 -iso-PGF ${ }_{2 \alpha}, 12$-HETE and 13-HODE were found in plasma from DE-exposed mice. ${ }^{7}$ A role for lipid peroxidation in mediating PM-induced atherosclerosis was reported in mice with increased plasma levels of 9-HODE and 12-HETE. ${ }^{22}$ Additionally, proinflammatory and cancer-promoting effects were reported for $\mathrm{PGE}_{2}$ and by contrast, $\mathrm{PGD}_{2}$ was identified as suppressor of cell invasion and generally was reported as antitumourigenic. ${ }^{19}$ Increased levels of 5-HETE, 12-HETE and 15-HETE are also linked to carcinogenesis and CVD. ${ }^{72}$ To our knowledge, however, effects on circulating AA and eicosanoids in human plasma following occupational exposure to DE/DEP have not been investigated.

This study investigated the biological impact of DE/DEP exposure associated with tunnel finishing work. We aimed to identify effect biomarkers in PBMC and plasma from TFW compared with a referent group. Bulky DNA adducts and miRNA expression profiles in PBMC were measured by ${ }^{32} \mathrm{P}$-postlabelling and small RNA sequencing (sRNA-seq), respectively. Circulating free plasma AA and eicosanoids were analysed by liquid chromatography-tandem mass spectrometry (LC/MS/MS). Finally, expression of selected protein coding genes related to PAH-bioactivation and DNA adduct formation was explored by RT-qPCR.

\section{MATERIALS AND METHODS}

\section{Study group}

An occupational cross-sectional study was performed in Norwegian male TFW $(n=69)$ and referents $(n=69)$ working at the same/similar construction sites. In addition to a high level of exposure to DEP, some exposure to concrete dust may occur in TFW. Referents are administrative personnel, engineers, and outdoor road workers. Participants have mainly similar socioeconomic status. Referents may occasionally work inside tunnels for shorter time periods, and some exposure to asphalt and vehicle emission may occur. Generally, participants work for 11-12 days consecutively with 10-12 hours shifts, before a 9-day period off work. At the time of enrolment (2015-2016), the participants were employed by five different Norwegian companies working at eight construction sites in South Norway.

Blood samples were collected from each participant on a single occasion at the construction sites in between shifts and each participant filled out a questionnaire. Background information collected included work operations, age, body mass index (BMI), smoking habits: never-smoker; former-smoker (less than a year); former-smoker (more than a year); daily-smoker; partysmoker, use of respirators (yes, often; yes, rarely; no), respiratory diseases (chronic bronchitis, chronic obstructive lung disease) and allergies.

\section{Sample collection}

Blood was collected into EDTA tubes (BD Vacutainer K2E, Mediq Norge AS, Kløfta, Norway) and kept rotating EDTA blood was loaded onto a SepMate tube (StemCell Technologies, Cambridge, UK) preloaded with Ficoll (GE Healthcare, Oslo, Norway). Plasma was separated according to the manufacturer's instructions and stored at $-80^{\circ} \mathrm{C}$. PBMC were treated with $\mathrm{RBC}$ lysis buffer and stored as pellets at $-80^{\circ} \mathrm{C}$.

\section{${ }^{32} \mathrm{P}$-postlabelling}

DNA was isolated from PBMC by standard phenol/chloroform extraction. The nuclease $\mathrm{P}_{1}$ enrichment version of the thin-layer chromatography ${ }^{32} \mathrm{P}$-postlabelling assay was used to determine bulky DNA adduct formation. The procedure was performed essentially as described, ${ }^{10}$ with minor modifications. All samples were analysed blind and in duplicate. An external benzo(a)pyrene-7,8-dihydrodiol-9,10-epoxide (BPDE)-modified DNA-standard was used as a positive control. Total DNA adduct levels were considered representative of PAH-DNA and other aromatic/hydrophobic adducts resistant to nuclease $\mathrm{P}_{1}$ digestion and measured in the diagonal radioactive zone. The method provides a summary measure of a complex mixture of adducts present in the postlabelling chromatograms. Results are expressed as adducts $/ 10^{8}$ nucleotides. Representative autoradiographic profiles of DNA adducts from never-smoking referents and TFW, daily-smoking TFW and an external BPDE-modified DNA-standard positive control are shown in online supplementary figure 1.

\section{Isolation of total-RNA}

RNA was isolated from PBMC using Trizol (Thermo Fisher Scientific, Oslo, Norway), dissolved in nuclease free water, and stored at $-80^{\circ} \mathrm{C}$. RNA-integrity number (RIN) was determined on an Agilent Bioanalyzer with RNA 6000 Nano kit (Agilent Technologies, Oslo, Norway). RIN values were in all cases $\geq 7.0$. 


\section{Measurement of gene expression}

RNA was reverse transcribed with the qScript complimentary DNA (cDNA) synthesis kit (Quanta Biosciences, VWR International, Oslo, Norway). qPCR reactions were set up with PerfeCTa SYBR Green Fastmix (ROX) (Quanta Biosciences, VWR International). Relative gene expression was normalised to the expression of RNA18S and calculated using the $\Delta \Delta \mathrm{Ct}$ method. Primers (online supplementary table 1) were purchased from Sigma-Aldrich or Thermo Fisher Scientific.

\section{Small RNA sequencing (sRNA-seq)}

Libraries for sRNA-seq were prepared using QIAseq miRNA Library kit (Qiagen, Hilden, Germany). Briefly, adapters were ligated to the 3' and 5' ends of miRNAs. sRNAs with ligated adapters underwent reverse transcription with unique molecular identifier (UMI) assignment followed by library amplification (16 cycles) on a Mastercycler Nexus (Eppendorf, Hamburg, Germany). sRNA libraries were validated on an Agilent 2100 Bioanalyzer (Agilent, Santa Clara, California, USA) using high-sensitivity DNA chips. Sequencing of sRNA libraries was performed on MiSeq system (Illumina, San Diego, California, USA) using MiSeq Reagent Kit V.3.

\section{Analysis of AA and eicosanoids}

Solid-phase extraction was used for AA metabolites (AA, PG, HETE, HODE, epoxyeicosatrienoic acids and leukotriene $\mathrm{A}_{4}$ ) from $0.5 \mathrm{~mL}$ human plasma samples. Analysis of plasma AA and eicosanoids by LC/MS/MS was performed as previously described. ${ }^{4} \mathrm{PGI}_{2}$ was determined as its non-enzymatically hydrolysed product 6-keto-PGF ${ }_{1 \alpha}$.

\section{Statistics}

Data were analysed in StataSE V.14. DNA adduct measurements and gene expression data were log-transformed to normalise the distribution of the error terms and analysed by linear regression. Differential miRNA expression count data were generated by QIAseq miRNA Quantification, and the UMI counts were taken to compensate for sequencing bias. The DESeq2-package was used to test for differential expression by the application of negative binomial generalised linear models. Differential expression in experimental designs with two levels of a factor (TFW vs referents) was tested by Wald. A p $<0.02$ was used as cut-off for statistically significant deregulated miRNAs between TFW and referents. miRNA target genes and associated pathways were identified using DIANA mirPath V.3 and TarBase V.7.0 (accessed July 2018) with $\mathrm{p}<0.05$ (Fisher's exact test, false discovery rate (FDR) correction). Prior to analysis, some of the eicosanoid variables were transformed, using a square-root, log, or inverse transformation, to obtain a closer fit to the normal distribution for the residuals. Each variable was analysed by linear regression. Smoking was included in the analyses, while age and BMI were only added if $\mathrm{p}<0.1$. Based on likelihood ratio tests, the residual variance was allowed to differ between referents and TFW for one outcome variable.

\section{RESULTS}

\section{Subject characteristics}

TFW $(n=69)$ and referents $(n=69)$ participated in the study by giving one blood sample during a random workday in addition to filling out a questionnaire. All subjects were Caucasian men. Few workers reported wearing protective respirators or filtering half masks. Compared with referents, TFW were significantly younger and were more inclined to tobacco smoking (table 1). Other

\begin{tabular}{|c|c|c|c|}
\hline & Referents & TFW & $P$ values \\
\hline Participants & $\mathrm{n}=69(\%)$ & $\mathrm{n}=69(\%)$ & \\
\hline \multicolumn{4}{|l|}{ Age } \\
\hline Overall mean \pm SD & $50.0 \pm 13.2$ & $41.0 \pm 12.2$ & $6.0 \times 10^{-5 *}$ \\
\hline \multicolumn{4}{|l|}{ Gender (\%) } \\
\hline Male & $69(100)$ & $69(100)$ & \\
\hline \multicolumn{4}{|l|}{ Ethnic group (\%) } \\
\hline Caucasian & $69(100)$ & $69(100)$ & \\
\hline Smoking history (\%)‡ & & & $0.003 \dagger$ \\
\hline Never-smoker & $28(41)$ & $17(25)$ & \\
\hline $\begin{array}{l}\text { Former-smoker (less } \\
\text { than a year) }\end{array}$ & $1(2)$ & $6(9)$ & \\
\hline $\begin{array}{l}\text { Former-smoker (more } \\
\text { than a year) }\end{array}$ & $19(28)$ & $11(16)$ & \\
\hline Daily-smoker & $8(12)$ & $24(35)$ & \\
\hline Party-smoker & $11(16)$ & $11(16)$ & \\
\hline BMI (SD)§ & $27.5(3.7)$ & $27.2(3.9)$ & \\
\hline Respirator mask (\%)ף & & & $0.001 \dagger$ \\
\hline Yes, often & $1(1)$ & $5(7)$ & \\
\hline Yes, rarely & $26(38)$ & $43(62)$ & \\
\hline No & $42(61)$ & $20(29)$ & \\
\hline \multicolumn{4}{|l|}{$\begin{array}{l}\text { Respiratory diseases } \\
(\%)^{* *}+\dagger\end{array}$} \\
\hline Chronic bronchitis & $3(4)$ & $1(1)$ & \\
\hline $\begin{array}{l}\text { Chronic obstructive lung } \\
\text { disease }\end{array}$ & $1(1)$ & $0(0)$ & \\
\hline \multicolumn{4}{|c|}{ 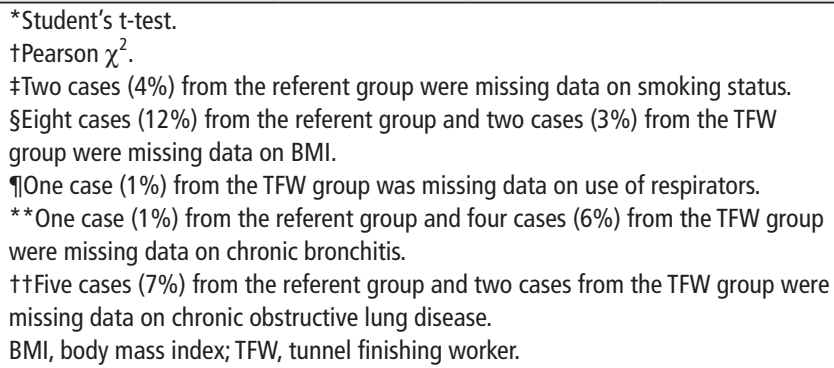 } \\
\hline
\end{tabular}

relevant parameters were not significantly different between TFW and referents.

\section{Bulky DNA adducts}

When stratified by smoking, significantly more DNA adducts were measured in PBMC from TFW compared with referents. In the referent group, daily-smokers had significantly more DNA adducts compared with never-smokers. Equivalently, dailysmoking TFW had significantly more DNA adducts compared with never-smoking TFW (figure 1A).

\section{Gene expression of CYP1A1 and CYP1B1}

Expression of CYP1A1 and CYP1B1 was measured in PBMC from never-smoking and daily-smoking TFW and referents. Significantly higher expression of CYP1B1 was found among TFW compared with referents (figure 1B). Interestingly, there were no effect modifications by smoking. Expression of CYP1A1 was below the detection limit, and expressions of AHR and ARNT were not significantly different between the groups (data not shown).

\section{Identification of deregulated miRNAs and associated pathways}

sRNA-seq was performed on samples from never-smoking TFW $(n=14)$ and referents $(n=13)$ matched by age and BMI. 
A

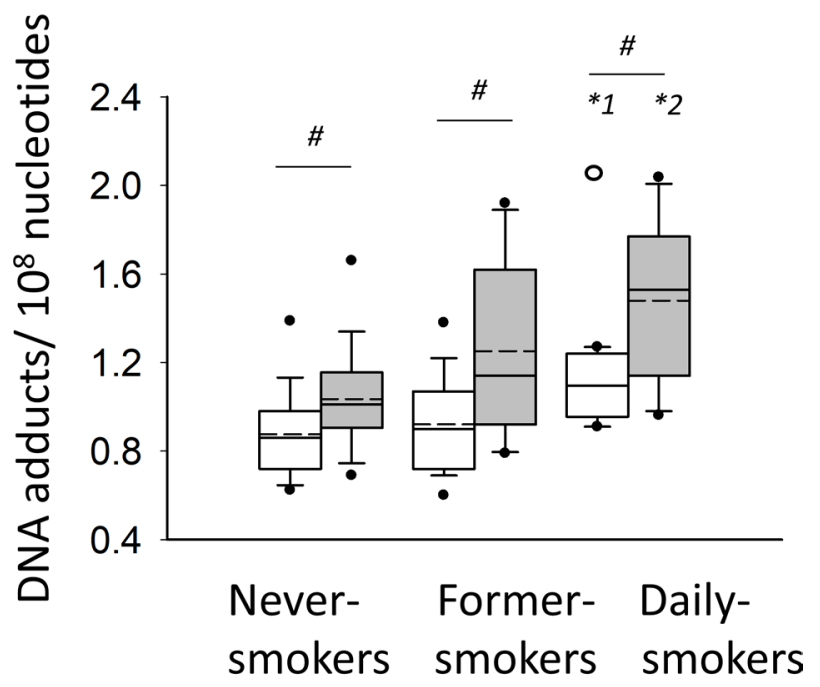

B

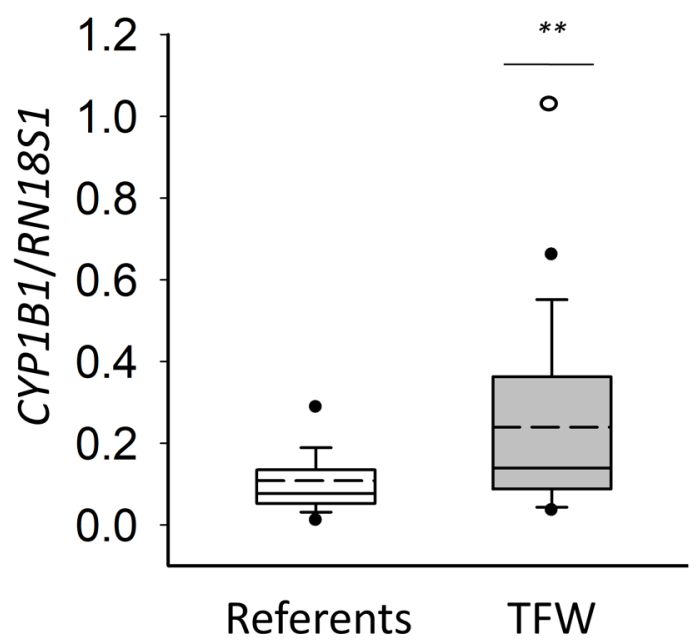

Figure 1 Bulky DNA adducts and CYP1B1 gene expression in PBMC from TFW and referents. (A) DNA adducts per $10^{8}$ nucleotides in three smoking categories; never-smokers ( $n=27 / 17)$, former-smokers $(n=19 / 16)$ and daily-smokers $(n=7 / 21)$. (B) Gene expression of CYP1B1 in referents $(n=36)$ and TFW $(n=41)$. Box plots show 5th/95th percentile, median (solid line) and mean (dotted line). Referents are shown in white and TFW in grey boxes. Two extreme outliers marked with unfilled circles (one referent, daily-smoker (A) and one TFW, never-smoker (B) are excluded from the statistical analysis. $\mathrm{P}<0.05$ (linear regression). ${ }^{*}$, significance between never-smokers and daily-smokers within the referents $\left({ }^{* 1}\right)$ and the TFW group $\left({ }^{* 2}\right)$, respectively. ${ }^{* *}$, significance between referents and TFW. \#, significance between referents and TFW within each smoking category. TFW, tunnel finishing worker.

Seventeen miRNA $(13(\downarrow), 4(\uparrow))$ were identified as deregulated in TFW compared with referents $(\mathrm{p}<0.02)$ (table 2$)$.

Experimentally supported miRNA-gene interactions followed by pathway analysis were obtained for deregulated miRNAs (table 2) by DIANA mirPath and TarBase. Ten Kyoto Encyclopedia of Genes and Genomes (KEGG) pathways were significantly deregulated based on presumptive miRNAgene target interactions (table 3). The pathways fatty acid
Table 2 Deregulated miRNAs identified by sRNA-seq

\begin{tabular}{lll}
\hline miRNA & log2FoldChange & P values \\
\hline hsa-miR-4700-5p & -0.80 & 0.002 \\
\hline hsa-miR-5701 & -0.75 & 0.002 \\
\hline hsa-miR-340-3p & -0.48 & 0.003 \\
\hline hsa-miR-6513-3p & 0.44 & 0.009 \\
\hline hsa-miR-20b-5p & 0.47 & 0.010 \\
\hline hsa-miR-3614-5p & -0.63 & 0.010 \\
\hline hsa-miR-106a-3p & 0.57 & 0.011 \\
\hline hsa-miR-660-3p & -0.59 & 0.012 \\
\hline hsa-miR-4288 & -0.56 & 0.012 \\
\hline hsa-miR-31-5p & 0.45 & 0.013 \\
\hline hsa-miR-23a-5p & -0.57 & 0.013 \\
\hline hsa-miR-196b-5p & -0.54 & 0.015 \\
hsa-miR-3130-3p & -0.61 & 0.015 \\
\hline hsa-miR-6808-3p & -0.57 & 0.016 \\
\hline hsa-miR-548an & -0.51 & 0.017 \\
hsa-miR-6828-5p & -0.60 & 0.018 \\
\hline hsa-miR-652-3p & -0.52 & 0.019 \\
\hline The table display deregulated miRNAs $p<0.02$ (Wald) as identified by sRNA-seq. \\
sRNA-seq, small RNA sequencing.
\end{tabular}

biosynthesis and metabolism, steroid biosynthesis, proteoglycans in cancer and cell cycle may be of particular importance. Further information regarding miRNA-gene targets and their clustering are found in online supplementary table 2 and figure 2 , respectively.

\section{Circulating $A A$ and eicosanoids}

Circulating free plasma AA and eicosanoids were measured in a subset of never-smoking and daily-smoking TFW and referents (table 4). Significantly more AA and 15-HETE, and significantly less PGD were found in TFW compared with referents. Compared with never-smoking referents, significantly less 9-HODE was measured in never-smoking TFW. Concentrations of all measured metabolites, although not significantly affected, are found in online supplementary table 3.

Table 3 Deregulated KEGG pathways associated with miRNA-gene targets

\begin{tabular}{llcc}
\hline Deregulated pathways & No miRNAs & No genes & P values \\
\hline Fatty acid biosynthesis & 1 & 1 & $<1.0 \mathrm{E}-325$ \\
\hline Prion diseases & 1 & 4 & $3.9 \mathrm{E}-12$ \\
Steroid biosynthesis & 4 & 3 & $3.6 \mathrm{E}-07$ \\
\hline Fatty acid metabolism & 1 & 1 & $6.7 \mathrm{E}-03$ \\
$\begin{array}{l}\text { Transforming growth factor- } \beta \\
\text { signalling pathway }\end{array}$ & 3 & 20 & $1.1 \mathrm{E}-02$ \\
\hline Viral carcinogenesis & 3 & 32 & $1.7 \mathrm{E}-02$ \\
\hline $\begin{array}{l}\text { Pantothenate and coenzyme A } \\
\text { biosynthesis }\end{array}$ & 1 & 1 & $3.5 \mathrm{E}-02$ \\
\hline Lysine degradation & 6 & 13 & $3.8 \mathrm{E}-02$ \\
\hline Proteoglycans in cancer & 4 & 42 & $4.4 \mathrm{E}-02$ \\
Cell cycle & 3 & 27 & $4.8 \mathrm{E}-02$ \\
\hline
\end{tabular}

Deregulated KEGG pathways associated with genes targeted by miRNA identified from sRNA-seq (table 3) using mirPath V.3 and TarBase V.7.0. P $<0.05$ (Fisher's exact test, FDR correction). Further information regarding miRNAs and genes is provided in online supplementary table 2 .

sRNA-seq, small RNA sequencing. 
Table 4 Circulating levels of AA and eicosanoids significantly differing in referents and TFW

\begin{tabular}{|c|c|c|c|c|c|c|c|}
\hline Metabolite* & Group & Subgroup & $\mathrm{n}$ & Mean (SD) & Median (Q)† & $P$ values & \\
\hline \multirow[t]{4}{*}{ AA§ (invers) } & Referents & Never-smokers & 13 & $217.1(34.5)$ & $207.0(164.0,288.7)$ & $x ף$ & $\mathrm{y}^{* *}$ \\
\hline & & Daily-smokers & 8 & $249.0(96.5)$ & $220.4(166.1,480.5)$ & 0.412 & \\
\hline & TFW & Never-smokers & 14 & $259.8(81.2)$ & $235.8(190.6,504.0)$ & 0.086 & 0.002 \\
\hline & & Daily-smokers & 24 & $336.6(124.9)$ & $298.5(195.1,577.3)$ & $<0.001$ & \\
\hline \multirow[t]{4}{*}{$\mathrm{PGD}_{2}$ (square root) } & Referents & Never-smokers & 12 & $24.7(13.0)$ & $22.9(8.1,48.5)$ & $x \Uparrow$ & $y^{* *}$ \\
\hline & & Daily-smokers & 8 & $24.4(14.1)$ & $23.9(5.0,44.8)$ & 0.852 & \\
\hline & TFW & Never-smokers & 14 & $15.9(6.3)$ & $16.0(7.5,28.0)$ & 0.034 & 0.002 \\
\hline & & Daily-smokers & 24 & $14.9(8.3)$ & $13.9(4.0,27.9)$ & 0.004 & \\
\hline \multirow[t]{4}{*}{ 15-HETE (log) } & Referents & Never-smokers & 13 & $27.4(9.9)$ & $25.6(17.1,48.4)$ & $x \emptyset$ & $y^{* *}$ \\
\hline & & Daily-smokers & 8 & $36.4(24.6)$ & $29.9(8.5,73.6)$ & 0.672 & \\
\hline & TFW & Never-smokers & 14 & $36.1(18.0)$ & $34.2(8.5,79.7)$ & 0.311 & 0.041 \\
\hline & & Daily-smokers & 23 & $48.9(23.3)$ & $44.8(17.1,83.4)$ & 0.005 & \\
\hline \multirow[t]{4}{*}{ 9-HODE (log) } & Referents & Never-smokers & 13 & $349.0(163.2)$ & $348.9(117.7,636.1)$ & $x \|$ & $\mathrm{y}^{* *}$ \\
\hline & & Daily-smokers & 8 & $336.7(273.1)$ & $211.7(91.1,906.4)$ & 0.614 & \\
\hline & TFW & Never-smokers & 14 & $212.3(162.6)$ & $146.4(67.3,617.8)$ & 0.033 & 0.063 \\
\hline & & Daily-smokers & 24 & $334.1(326.5)$ & $230.5(60.6,976.4)$ & 0.22 & \\
\hline
\end{tabular}

*pg/mL, transformation method.

tQuantiles: 5\%, 95\%.

fLinear regression. Significant $p$ values $(p<0.05)$ in bold.

$\S n g / m L$.

Ix (referents, never-smokers) and ** y (referents, never-smokers and daily-smokers combined) denote the reference groups for the corresponding statistical analyses.

AA, arachidonic acid; 15-HETE, 15-hydroxyeicosatetraenoic acid; 9-HODE, 9-hydroxyoctadecadienoic acid; PGD, prostaglandin $\mathrm{D}_{2}$; TFW, tunnel finishing worker.

\section{DISCUSSION}

Detailed exposure measurements of dust, EC, organic carbon, and $\mathrm{NO}_{2}$ have been reported from various job groups related to drilling and blasting during tunnel construction in Norway. ${ }^{23}$ However, DE/DEP exposure from heavy-duty diesel-powered equipment during tunnel finishing work was only recently investigated. ${ }^{6}$ Here, molecular alterations in PBMC and blood plasma coherent with working in such an environment were investigated. Results indicated increased levels of bulky DNA adducts and changes in miRNA profiles in PBMC, as well as altered free plasma AA and eicosanoid profiles in TFW.

Stratified by smoking, significantly more DNA adducts were measured in PBMC from TFW compared with the referents. Similarly, more DNA adducts were measured in daily-smokers than never-smokers in both groups. It is established that smoking increases DNA adducts in PBMC. ${ }^{11}$ Here, results indicate that exposures encountered during present-day tunnel finishing work pose a further increased risk of developing DNA adducts in these cells. These findings are in line with previous studies investigating levels of DNA adducts in PBMC/WBC following exposure to $\mathrm{DE},{ }^{13} 1424$ and positive correlations between cigarette smoking and DNA adducts in PBMC. ${ }^{11}$ Taking into account that DNA adducts in bronchial tissue may predict lung cancer risk, ${ }^{25}$ and that adducts in PBMC can be considered a distant surrogate of pulmonary exposure, ${ }^{11}$ this finding may have important implications for risk assessment and preventive strategies concerning the group of TFW.

Levels of DNA adducts are dependent on the individual's xenobiotic metabolising capability. Significantly higher levels of CYP1B1 expression were measured in PBMC from TFW compared with referents. Interestingly, CYP1B1 expression was not influenced by smoking and CYP1A1 expression in PBMC was below the detection limit in agreement with a previous report. $^{26}$ AHR and ARNT were equally expressed in both groups. A crosstalk between the oestrogen receptor (ER) and the AHR pathway exists. ${ }^{27}$ Several PAHs present in DEP are shown to directly activate $\mathrm{ER} \alpha,{ }^{27}$ indicating that CYP1B1 may be induced by non-AHR-mediated mechanisms. Alternatively, endogenous availability of coactivators may play a role. ${ }^{27}$ Nonetheless, results suggest that CYP1B1, rather than CYP1A1 may have implications for DEP-induced DNA adduct formation in PBMC.

sRNA-seq revealed significant deregulation of 17 miRNAs in TFW compared with referents. Little is known about these miRNAs in relation to DE/DEP exposure from either occupational or air pollution studies. miR-106a-3p, being upregulated in TFW, has been reported as an oncomir in humans exposed to air pollution. ${ }^{16}$ miR-23a-5p was downregulated in TFW. Downregulation of miR-23a is associated with activation of apoptotic pathways, in addition to increased expression of the antioxidant superoxide dismutase [Mn], mitochondrial, which is important in mitochondrial reactive oxygen species detoxification. ${ }^{28}$ miR-31-5 p was upregulated in TFW and has been found to act as tumour suppressor and apoptotic inducer in both in vitro and in vivo air pollution studies. ${ }^{16}$ In agreement with the present study, downregulation of miR-652-3 p was also reported in human blood after short-term $\mathrm{PM}_{10}$ exposure. This miRNA has a putative role in CVD. ${ }^{29}$

The remaining deregulated miRNAs have not been studied in relation to DE/DEP exposure. Some are associated with lung and colorectal cancers and as possible prognostic markers (miR-20b-5p, miR-196b-5p, miR-4500 and miR-340), ${ }^{30-32}$ while others may have roles in Alzheimer's disease, chronic heart failure, and cell migration and invasion (miR-6513-3 $\mathrm{p}$ and miR-660-3 p). ${ }^{1633}$ Both miR-20b-5p and miR-196b-5p may be important regulator of apoptosis and tumourigenesis. ${ }^{32}$ Whether these miRNAs are related to adverse health effects of DE/DEP exposure is not known.

Pathway union analysis based on putative miRNA-gene targets revealed potential deregulation of several fatty acid related KEGG pathways in TFW, in addition to cell cycle, steroid biosynthesis, and proteoglycans in cancer. Exposure to air pollution is significantly associated with increased risk of type 2 diabetes mellitus. ${ }^{34}$ Subchronic exposure to low concentrations 
of $\mathrm{DE}$ is shown to deregulate genes related to fatty acid biosynthesis in mice. ${ }^{35}$ miRNAs may regulate cell cycle progression, ${ }^{36}$ and altered expression of cell cycle-related genes has been reported after exposure to organic components from DEP. ${ }^{37}$ Steroid biosynthesis is a target for endocrine disrupting chemicals, including PAHs. ${ }^{27}$ Interestingly, human bronchial epithelial cells exposed to DEP in vitro also showed deregulation of this pathway. ${ }^{4}$ Deregulation of proteoglycans in cancer may be of importance as this pathway of extracellular matrix constituents is emerging as highly affecting homoeostasis and progression of various diseases, including cancer. ${ }^{38}$ Combined, results indicate potential mechanisms for associations between miRNA-regulated pathways, increased levels of DNA adducts and altered plasma AA and eicosanoid profiles in TFW. Deregulated pathways may affect lung homoeostasis, carcinogenesis, inflammation status, and the cardiovascular system. Further research is needed to identify specific mechanisms behind deregulated miRNAs and associated pathways following occupational exposure to DE/DEP.

Little is known about free plasma AA and associated eicosanoids in response to DE/DEP exposure in vivo. In line with present findings, increased levels of plasma 15-HETE were found in PM-exposed mice. ${ }^{39}$ 15-HETE signalling is associated with cardiovascular pathogenesis, as well as cancer development. ${ }^{20}$ While we report reduced levels of $\mathrm{PGD}_{2}$ in TFW, an increase in this metabolite was measured in plasma from PM-exposed mice. ${ }^{39}$ Interestingly, the great majority of studies indicate antitumourigenic activities of $\mathrm{PGD}_{2}{ }^{19}$ Levels of 9-HODE was lower in neversmoking TFW compared with never-smoking referents, suggesting the involvement of antioxidant responses. Increased level of this metabolite has been measured in PM-exposed mice, ${ }^{22}$ but the modulation of oxidative stress and antioxidant defence processes may be time and dose dependent. Evidence indicates that gaseous $\mathrm{NO}_{2}$ is an independent risk factor for CVD. ${ }^{9}$ Since $\mathrm{NO}_{2}$, together with DEP and other DE constituents, can induce oxidative stress and inflammation, ${ }^{3578}$ it may be speculated that $\mathrm{NO}_{2}$ participates in $\mathrm{AA}$ and eicosanoid deregulation. Combined, present results suggest that in particular increased concentrations of AA and 15-HETE, and decreased levels of PGD and 9-HODE may represent biomarkers of exposure to DE/DEP. These analytes make up a complex network with the potential to modulate inflammation, cell growth responses and the cardiovascular system, but more research is needed to elucidate in detail their biological effects.

The carcinogenicity of DE/DEP to humans has been debated. ${ }^{40}$ Combined, this study indicates increased bulky DNA adducts in PBMC and deregulation of cancer and fatty acid-related pathways, as well as altered free plasma AA and eicosanoid signalling molecules, associated with working in a DE/DEP-polluted environment. Although not dealing with cancer risk per se, the results are in favour of DE/DEP having carcinogenic potential, which is supported by in vitro studies. ${ }^{45}$

Possible confounding due to the healthy worker effect is of general concern. Here, all participants were employed at the time of enrolment. Women were excluded because of low number of potential participants. The cross-sectional study design combined with the one blood sample obtained from each participant could have led to incidental results. However, grouping TFW and referents without major stratification limits the potential influence by such bias. The referents constitute a more heterogeneous group than the TFW and they may occasionally spend short time periods within tunnels. Combined, one could speculate that differences between TFW and referents may potentially be more pronounced than the current results indicate.

\section{CONCLUSION}

In conclusion, exposure to DE/DEP during tunnel finishing work is associated with biological alterations in TFW. This group of workers has been little studied regarding potential work-related adverse health effects. More attention should be directed towards describing biological effects and possible implications on health outcomes from occupational exposure to DE/DEP and, in particular, related to tunnel finishing work.

\section{Author affiliations}

'Section for Toxicology and Biological Work Environment, Department of Chemical and Biological Work Environment, National Institute of Occupational Health, Oslo, Norway

${ }^{2}$ Department of Analytical, Environmental and Forensic Sciences, MRC-PHE Centre for Environment and Health, King's College London, London, UK

${ }^{3} \mathrm{NIHR}$ Health Protection Research Unit in Health Impact of Environmental Hazards at King's College London in Partnership with Public Health England and Imperial

College London, London, UK

${ }^{4}$ Department of Genetic Toxicology and Nanotoxicology, Institute of Experimental Medicine of the Czech Academy of Sciences, Prague, Czech Republic

${ }^{5}$ Department of Chemistry and Toxicology, Veterinary Research Institute, Brno, Czech Republic

${ }^{6}$ Department of Computer Science, Czech Technical University in Prague, Prague, Czech Republic

${ }^{7}$ Department of Occupational Medicine and Epidemiology, National Institute of Occupational Health, Oslo, Norway

${ }^{8}$ Department of Work Psychology and Physiology, National Institute of Occupational Health, Oslo, Norway

Acknowledgements We thank Rita Bæra for skillful technical assistance. We also thank the workers and the tunnel construction companies participating in this study, in particular Kristin H Hovland (Occupational Health Physician).

Contributors Study design was led by IR and SM, with contributions from BU, PR, VMA, DHP, MM, JT and AH. IR, EP and BU carried out enrolment of participants and collection of human samples. Data collection was carried out by IR, VMA, KV, JN and PR. IR, ØS and JK conducted statistical analyses. IR drafted the manuscript. All authors participated in data analysis, critically revised the manuscript and approved the final version

Funding This work was financially supported by the Statoil Working Environment Fund (Norway) and the Ministry of Youth, Education and Sports of the Czech Republic (LO1508 to PR, JK and KV, LM2015073; CZ.02.1.01/0.0/0.0/16_013/00 01821 to JT; the grant Research Center for Informatics CZ.02.1.01/0.0/0.0/16 01 9/0000765 to JK; project "FIT", no. CZ.02.1.01/0.0/0.0/15_003/0000495 to MM and JN). Work at King's College London was supported by the National Institute for Health Research Health Protection Research Unit (NIHR HPRU) in Health Impact of Environmental Hazards at King's College London in partnership with Public Health England and Imperial College London.

Disclaimer The views expressed in this article are those of the authors and not necessarily those of the UK National Health Service, the UK National Institute for Health Research Health, the UK Department of Health and Social Care or Public Heath England.

Competing interests None declared.

\section{Patient consent Not required.}

Ethics approval The study was approved by the Norwegian Regional Committees for Medical and Health Research Ethics (REC \#2014/2199).

Provenance and peer review Not commissioned; externally peer reviewed.

Open access This is an open access article distributed in accordance with the Creative Commons Attribution Non Commercial (CC BY-NC 4.0) license, which permits others to distribute, remix, adapt, build upon this work non-commercially, and license their derivative works on different terms, provided the original work is properly cited, appropriate credit is given, any changes made indicated, and the use is non-commercial. See: http://creativecommons.org/licenses/by-nc/4.0/.

\section{REFERENCES}

1 Pronk A, Coble J, Stewart PA. Occupational exposure to diesel engine exhaust: a literature review. J Expo Sci Environ Epidemio/ 2009;19:443-57.

2 International Agency for Research on Cancer. Diesel and gasoline engine exhaust and some nitroarenes: IARC Monographs on the evaluation of carcinogenic risks to humans, 2014:105.

3 Sydbom A, Blomberg A, Parnia S, et al. Health effects of diesel exhaust emissions. Eur Respir J 2001;17:733-46. 
4. Rynning I, Neca J, Vrbova K, et al. In Vitro Transformation of Human Bronchial Epithelial Cells by Diesel Exhaust Particles: Gene Expression Profiling and Early Toxic Responses. Toxicol Sci 2018;166:51-64.

5 Schwarze PE, Totlandsdal Al, Låg M, et al. Inflammation-related effects of diesel engine exhaust particles: studies on lung cells in vitro. Biomed Res Int 2013;2013:685142.

6 Thomassen Y, Berlinger B, Ellingsen DG. Kartlegging av eksponering for dieseleksosartikler i norsk arbeidsliv ved bruk av elementært karbon som markør. STAMI-report 2015.

7 Yin F, Lawal A, Ricks J, et al. Diesel exhaust induces systemic lipid peroxidation and development of dysfunctional pro-oxidant and pro-inflammatory high-density lipoprotein. Arterioscler Thromb Vasc Biol 2013;33:1153-61.

8 Steiner S, Bisig C, Petri-Fink A, et al. Diesel exhaust: current knowledge of adverse effects and underlying cellular mechanisms. Arch Toxicol 2016;90:1541-53.

9 Faustini A, Rapp R, Forastiere F. Nitrogen dioxide and mortality: review and metaanalysis of long-term studies. Eur Respir J 2014;44:744-53.

10 Reed L, Mrizova I, Barta F, et al. Cytochrome b impacts on cytochrome P450mediated metabolism of benzo[a]pyrene and its DNA adduct formation: studies in hepatic cytochrome $b_{5}$ /P450 reductase null (HBRN) mice. Arch Toxicol 2018;92:1625-38.

11 Wiencke JK, Kelsey KT, Varkonyi A, et al. Correlation of DNA adducts in blood mononuclear cells with tobacco carcinogen-induced damage in human lung. Cancer Res 1995;55:4910-4.

12 Gilberson T, Peluso ME, Munia A, et al. Aromatic adducts and lung cancer risk in the European Prospective Investigation into Cancer and Nutrition (EPIC) Spanish cohort. Carcinogenesis 2014;35:2047-54.

13 Hemminki K, Söderling J, Ericson P, et al. DNA adducts among personnel servicing and loading diesel vehicles. Carcinogenesis 1994;15:767-9.

14 Nielsen PS, Andreassen A, Farmer PB, et al. Biomonitoring of diesel exhaust-exposed workers. DNA and hemoglobin adducts and urinary 1-hydroxypyrene as markers of exposure. Toxicol Lett 1996;86:27-37.

15 Duan $H$, Jia X, Zhai Q, et al. Long-term exposure to diesel engine exhaust induces primary DNA damage: a population-based study. Occup Environ Med 2016;73:83-90.

16 Vrijens K, Bollati V, Nawrot TS. MicroRNAs as potential signatures of environmental exposure or effect: a systematic review. Environ Health Perspect 2015;123:399-411.

17 Yamamoto M, Singh A, Sava F, et al. MicroRNA expression in response to controlled exposure to diesel exhaust: attenuation by the antioxidant $N$-acetylcysteine in a randomized crossover study. Environ Health Perspect 2013;121:670-5.

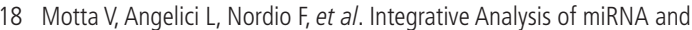
inflammatory gene expression after acute particulate matter exposure. Toxico/ $\mathrm{SCi}$ 2013;132:307-16.

19 Wang D, Dubois RN. Eicosanoids and cancer. Nat Rev Cancer 2010;10:181-93.

20 Moreno JJ. New aspects of the role of hydroxyeicosatetraenoic acids in cell growth and cancer development. Biochem Pharmacol 2009;77:1-10.

21 Møller P, Loft S. Oxidative damage to DNA and lipids as biomarkers of exposure to air pollution. Environ Health Perspect 2010;118:1126-36.
22 Li R, Navab M, Pakbin P, et al. Ambient ultrafine particles alter lipid metabolism and HDL anti-oxidant capacity in LDLR-null mice. J Lipid Res 2013;54:1608-15.

23 Bakke B, Ulvestad B, Thomassen Y, et al. Characterization of occupational exposure to air contaminants in modern tunnelling operations. Ann Occup Hyg 2014;58:818-29.

24 Schoket B, Phillips DH, Hewer A, et al. 32P-postlabelling detection of aromatic DNA adducts in peripheral blood lymphocytes from aluminium production plant workers. Mutat Res 1991;260:89-98.

25 Ceppi M, Munnia A, Cellai F, et al. Linking the generation of DNA adducts to lung cancer. Toxicology 2017;390:160-6.

26 Tuominen R, Warholm M, Möller L, et al. Constitutive CYP1B1 mRNA expression in human blood mononuclear cells in relation to gender, genotype, and environmental factors. Environ Res 2003;93:138-48.

27 Shanle EK, Xu W. Endocrine disrupting chemicals targeting estrogen receptor signaling: identification and mechanisms of action. Chem Res Toxicol 2011;24:6-19.

28 Long B, Gan TY, Zhang RC, et al. miR-23a regulates cardiomyocyte apoptosis by targeting manganese superoxide dismutase. Mol Cells 2017;40:542-9.

29 Pergoli L, Cantone L, Favero C, et al. Extracellular vesicle-packaged miRNA release after short-term exposure to particulate matter is associated with increased coagulation. Part Fibre Toxicol 2017;14:32-214.

30 Zhang L, Qian J, Qiang Y, et al. Down-regulation of miR-4500 promoted non-small cell lung cancer growth. Cell Physiol Biochem 2014;34:1166-74.

31 Takeyama H, Yamamoto H, Yamashita S, et al. Decreased miR-340 expression in bone marrow is associated with liver metastasis of colorectal cancer. Mol Cancer Ther 2014;13:976-85

32 Slattery ML, Mullany LE, Sakoda LC, et al. Dysregulated genes and miRNAs in the apoptosis pathway in colorectal cancer patients. Apoptosis 2018;23:237-50.

33 Satoh J, Kino Y, Niida S. MicroRNA-seq data analysis pipeline to identify blood biomarkers for alzheimer's disease from public data. Biomark Insights 2015; 10:21-31.

34 Meo SA, Memon AN, Sheikh SA, et al. Effect of environmental air pollution on type 2 diabetes mellitus. Eur Rev Med Pharmaco/ Sci 2015;19:123-8.

35 Umezawa M, Nakamura M, El-Ghoneimy AA, et al. Impact of diesel exhaust exposure on the liver of mice fed on omega-3 polyunsaturated fatty acids-deficient diet. Food Chem Toxicol 2018;111:284-94.

36 Carleton M, Cleary MA, Linsley PS. MicroRNAs and cell cycle regulation. Cell Cycle 2007:6:2127-32.

37 Libalova H, Rossner P, Vrbova K, et al. Comparative analysis of toxic responses of organic extracts from diesel and selected alternative fuels engine emissions in human lung BEAS-2B Cells. Int J Mol Sci 2016;17:1833.

38 Nikitovic D, Berdiaki A, Spyridaki l, et al. Proteoglycans-biomarkers and targets in cancer therapy. Front Endocrinol 2018;9:69.

39 Li R, Navab K, Hough G, et al. Effect of exposure to atmospheric ultrafine particles on production of free fatty acids and lipid metabolites in the mouse small intestine. Environ Health Perspect 2015;123:34-41.

$40 \mathrm{HEl}$ Diesel Epidemiology Panel. Diesel emissions and lung cancer: an evaluation of recent epidemiological evidence for quantitative risk assessment. 2015:19. 